\title{
NAVEGAR É PRECISO... LETRAR, TAMBÉM!: LETRAMENTOS DIGITAIS, PRÁTICAS EDUCACIONAIS E DISCUSSÕES EMERGENTES
}

\author{
SAILING IS NECESSARY... LETTERING, TOO!: \\ DIGITAL LITERACIES, EDUCATIONAL PRACTICES \\ AND EMERGING DISCUSSIONS
}

\author{
Jennifer da Silva Gramiani Celeste* \\ Juliana Célia de Oliveira ${ }^{* *}$
}

\begin{abstract}
RESUMO: Na atual temporalidade, o educando, além de outras possíveis atribuições a ele vinculadas, é também \#superconectado e, por isso, escreve e lê no ciberespaço por intermédio das telas de seus smartphones, tablets, e-readers e demais artigos. Logo, em contraste à cultura impressa introduzida e reforçada pela escola enquanto instituição responsável pela transmissão de saberes, os Letramentos Digitais encontram - ou não - espaço pertinente à sua abordagem. O presente artigo objetiva debater como as práticas de escrita e leitura foram transfiguradas a partir do advento das TIC, na transição entre o velho e o novo milênio, considerando, ainda, como isso é percebido no âmbito educacional. Para alcançar esse feito, embasamos nossa pesquisa em fontes e referenciais considerados fundamentais à compreensão da temática. Constatamos a necessidade de se refletir acerca da escola tradicional da contemporaneidade digital e as implicações dessa dinâmica à formação de cidadãos críticos, conscientes e - inevitavelmente \#superconectados.
\end{abstract}

Palavras-chave: Letramentos Digitais. Educação. Escrita. Leitura.

ABSTRACT: In the current temporality, the student, in addition to other possible assignments linked to him, is also \#superconnected and, therefore, writes and reads in cyberspace through the screens of his smartphones, tablets, e-readers and other articles. Therefore, in contrast to the printed culture introduced and reinforced by the school as an institution responsible for the transmission of knowledge, the Digital Literacies find - or not - space relevant to its approach. This article aims to debate how writing and reading practices were transfigured from the advent of ICT, in the transition between the old and the new millennium, also considering how this is perceived in the educational field. To achieve this feat, we base our research on sources and references considered fundamental to the understanding of the theme. Finally, we note the need to reflect on the traditional contemporary digital school and the implications of this dynamic for the formation of critical, aware and - inevitably - \#superconnected citizens.

Keywords: Digital Literacies. Education. Writing. Reading.

\section{Introdução}

Contrariamente às obscuras expectativas lançadas por estudiosos da área, as práticas de escrita e leitura propiciadas pela nova revolução tecnológica, ocorrida a partir da década de 1990 com o surgimento dos computadores conectados à rede, têm demonstrado fôlego e persistência capazes de causar incômodo até mesmo em território ainda não devidamente explorado, tal como a escola. Resistências e inconsistências assinalam, então, os discursos daqueles que demonstram aparentar não reconhecer a realidade hoje vigente, assinalada pela presença cada vez mais constante das máquinas na vida de um dos protagonistas desse cenário, os estudantes. Como consequência disso,

\footnotetext{
* Universidade Federal de Juiz de Fora. Doutoranda em Letras (Estudos Literários) pela Universidade Federal de Juiz de Fora. E-mail: djeceleste@gmail.com

** Faculdade Metodista Granbery.Doutora em Psicologia pela Universidade Federal de Juiz de Fora Email: julianaoliveirapsi@gmail.com
} 
temos também a presença de projeções e protótipos das manifestações virtuais nas salas de aula, indo muito além dos convencionais e legitimados atos de escrita e leitura.

Este artigo se propõe a expor e a discutir o panorama que a era digital nos deixa como uma herança cotidiana, especialmente no que se refere ao âmbito escolar. Discorrer acerca das práticas de escrita e leitura empreendidas nesta temporalidade, e não menos importante, suscitar reflexões sobre as implicações da dinâmica em destaque no interior das instituições escolares e do sistema educacional, são os objetivos que pretendemos alcançar. Logo, para esse feito, recorremos a fidedignos subsídios teóricos os quais puderam nos auxiliar a respeito da imersão no tema selecionado para o estudo.

Sob um claro movimento de alternância entre teclar, escrever à mão, correr os olhos de modo superficial ou desenvolver uma leitura atenta e cerrada, o aprendiz da escola contemporânea equilibra-se na delicadeza exacerbada da fibra óptica, mas também nas páginas dos títulos impressos. Eis uma questão: superconectar-se ou não, quando um mundo de possibilidades os convoca direto das janelas virtuais, mas os paradigmas da escola tradicional insistem em contê-los sob os seus muros? Devemos lembrar que navegar é preciso, e letrar, também. Iniciemos, então, a nossa rota.

\section{Escrita e leitura na cultura digital: aspectos históricos}

Reportando-nos aos primórdios da gênese da grande rede de computadores, é possível constatarmos que os blogs se constituíram as principais ferramentas virtuais por intermédio das quais foi possibilitada aos internautas e usuários a expressão via publicação textual - os posts. Entre os principais servidores de origem nacional, estavam o Weblogger - Terra - e o Zip Net - UOL. Blogger, mantido pela Google, foi e talvez ainda se configure aquele que detém o maior número de adeptos às práticas de postagem online - popularmente conhecidos como blogueiros. As complexas interfaces e os inusitados layouts jamais foram capazes de impedir que os curiosos se deleitassem satisfatoriamente por entre a divulgação de posts ou comentários. Em meados do novo milênio, os blogs da autoria de jovens internautas dedicavam-se não apenas à escritura subjetiva, mas, sobretudo, aos seus ídolos, provenientes da música ou da televisão. Aliás, era comum possuir e manter mais de uma webpage no ar, dividindo-se entre a partilha de situações de cunho pessoal ou a postagem de novidades sobre celebridades.

Decerto, talvez por questões de sobrevivência diante do surgimento das redes sociais e plataformas propiciadoras de expressão no meio virtual, os objetivos até então inerentes à utilização dos blogs - estabelecimento de vínculos sociais e disseminação de conteúdos diversos, por exemplo - se modificou na contemporaneidade vigente, tendo sido interceptada por elementos atrelados às comuns práticas de espetáculo, às relações de consumo e à demasiada oferta de entretenimento. Hoje, verificamos, exceto por alguns poucos casos, uma utilização calcada na prerrogativa do acúmulo de seguidores.

Concomitante ao fortalecimento dos blogs na rede cibernética, não devemos nos olvidar, ainda em meados dos anos de 1990, da prevalência das salas de bate-papo ou chats. Indubitavelmente, responsáveis pela massiva popularização das abreviações, das gírias e do dialeto típico do meio eletrônico - o popular internetês -, esses espaços virtuais ofertados aos navegantes a fim de que pudessem dialogar junto aos pares, partilhar interesses comuns e se ajudarem mutuamente, também instituiu o verdadeiro desencanto de muitos dos profissionais vinculados à área educacional, haja vista que a partir de sua origem e seu crescente número de adeptos, as práticas de escrita se transfiguraram por completo e inevitavelmente, localizando-se distantes dos ideais preconizados por ambientes escolares e acadêmicos. Nesse âmbito, o programa de envio 
e recebimento de mensagens instantâneas $I C Q$, idealizado por jovens israelenses no ano de 1996, merece o devido destaque por sua legitimidade quanto à proposta de promoção de diálogos e compartilhamentos virtuais entre os internautas, embora seus recursos atualmente possam ser considerados rudimentares em virtude das várias e modernas ferramentas disponibilizadas ao público conectado. É precursor do MSN Messenger, software online responsável por popularizar os emoticons ${ }^{1}$ e a utilização das webcams. What's App, aplicativo para smartphones, é tido como a sua evolução na atualidade, reforçando ainda mais o emprego de uma linguagem outrora preconizada pelos usuários dos modernos hardwares conectados à grande rede. Facebook e Instagram também apresentam opções para o estabelecimento de diálogo entre os seguidores, o que torna possível o envio de áudios, imagens, vídeos e posts publicados nessas mídias sociais.

$\mathrm{O}$ artigo "Escrevo abreviado porque é muito mais rápido": o adolescente, o internetês e o letramento digital" (2009), dos estudiosos Messias Dieb e Flávio Avelino, trazem alguns interessantes conceitos, por ora necessários às nossas imersões no terreno relativo à escrita cibernética. Segundo esses autores, as peculiaridades da manifestação escrita do meio virtual só vieram a se fazer presentes em nosso cotidiano devido ao advento dos chats, já anteriormente mencionados. Justamente por oferecer diálogo simultâneo entre os indivíduos, os chatters $^{2}$ são impostos a distintas desenvolturas em relação à escrita. Comumente, as dúvidas circundam nossa compreensão quanto ao internetês, mas os autores o conceituam "[...] como uma variedade escrita da língua portuguesa, à qual foi atribuído o estilo abreviado de escrita que é típico na maioria dos gêneros do universo digital [...]" (DIEB; AVELINO, 2009, p. 265).

Por óbvio, o transcorrer dos anos e a evolução das novas tecnologias digitais foram capazes de tornar ainda mais nuançadas as viabilidades de ser, estar e se expressar no meio virtual. Atualmente, paralelo aos blogs e chats, há à disposição um grande arsenal de redes sociais, cada qual detentora de especificidades à escrita. Logo, do Twitter e seus rígidos duzentos e oitenta caracteres, perpassando pelo Instagram e suas hashtags e, por fim, alcançando as publicações no Facebook, adornadas de links, diversas são as configurações que hoje a expressão escrita assume em tempos digitais.

Também há outras viabilidades ciberespaciais em vista da notável eclosão das plataformas virtuais de autopublicação literária. Seguramente, Wattpad foi um dos primeiros serviços eletrônicos - ao menos neste milênio, já que iniciou seus trabalhos no ano de 2006 - a possibilitar a produção e o compartilhamento de textos literários ${ }^{3}$ no contexto de uma comunidade virtual. Podemos ainda citar a existência de outros tantos websites congêneres, tais como Niah! Fanfiction, Spirit Fanfics e WidBook.

Desse modo, idealizam-se histórias multimodais, permeadas por linguagens verbais, visuais e sonoras. São esses e outros aspectos semelhantes que constituem aquilo o que Katherine Hayles denomina como Literatura Eletrônica no título Literatura eletrônica: novos horizontes para o literário (2009). Tal singular manifestação literária, cuja origem aconteceu junto àquela referente aos computadores digitais, à medida na qual suas proporções se tornaram mais diminutas, é caracterizada como "[...] obra com um aspecto literário importante que aproveita as capacidades e contextos fornecidos por um computador independente ou em rede [...]" (HAYLES, 2009, p. 21). Em uma linha de raciocínio similar, Janet Murray, autora à frente de Hamlet no holodeck: o futuro da

\footnotetext{
1 Ícones ilustrativos de expressões faciais, os emoticons traduzem um estado de espírito, sendo hoje também conhecidos como emojis, que abarcam diversas categorias, entre animais, objetos e alimentos.

${ }^{2}$ Nomenclatura utilizada para denominar os internautas adeptos às salas de bate-papo.

${ }^{3}$ Pretendemos não nos ater à literariedade que atribui a um texto o caráter literário, já que a discussão sobre o tema é circundada por complexidades acerca das quais não nos compete aqui debater.
} 
narrativa no ciberespaço (2003), expressa acreditar que os computadores, máquinas detentoras de eloquente "[...] poder caleidoscópico [...]" (MURRAY, 2003, p. 59), permitem aos internautas-escritores criar histórias as quais refletem o cenário cultural e social típico da transição entre os séculos. Portanto, essas narrativas se desenvolvem com base no panorama de tempos contemporâneos, eletrônicos e multimodais.

Devemos nos atentar, diante das possibilidades que os textos hoje assumem, também às transfigurações que permeiam o ato de leitura na atualidade digital, considerando, para tanto, não apenas os novos modos de produção trazidos à luz pela gênese da eletrônica, mas também seus diversos suportes. Progressivamente, as folhas de celulose, até então únicas e exclusivas fontes de leitura no último século, viram-se obrigadas a conceder espaço às telas comuns e touchs pertencentes aos computadores, tablets, smartphones e e-readers - este cenário, em razão da gradual expansão das novas tecnologias digitais. Nos diálogos entre Umberto Eco e Jean-Claude Carrière, presentes na obra Não contem com o fim do livro (2010), os críticos se debruçam sobre questões concernentes à imaterialidade que assumem os suportes vinculados às práticas de leitura no presente milênio, defendendo argumentos à mantença da produção dos livros impressos - "[...] o livro se apresenta como uma ferramenta mais flexível [...]" (ECO; CARRIÈRE, 2010, p. 9) -, expondo as desvantagens dos dispositivos eletrônicos - "[...] o computador depende da eletricidade e não pode ser lido numa banheira, tampouco deitado na cama [...]" (ECO; CARRIÈRE, 2010, p. 9).

Todavia, ainda que possamos atualmente vislumbrar melhores perspectivas às práticas de leitura em suportes materiais - a julgar pelo expressivo engajamento dos grupos editoriais brasileiros no que se refere à idealização de selos e nichos literários dedicados à jovem parcela populacional -, a imersão por entre as linhas que delineiam as narrativas em questão também ocorre na virtualidade propiciada pelas telas, pois essa se configura realidade vigente, hoje representada por e-books. Sua história remonta a quarenta anos, de acordo com Carlos Pinheiro, autor do artigo "Novos cenários e suportes de leitura" (2012). Apesar de criados por Michael Hart em meados da década de 1970, a leitura desses arquivos, à época, fazia-se possível apenas em computadores convencionais. Porém, anos mais tarde, os avanços tecnológicos possibilitaram aos usuários desses materiais a realização de leitura em compactos e portáteis hardwares, tais como o Rocket, lançado em 1996, cuja memória possuía dezesseis megabytes.

Os e-readers são dispositivos de natureza eletrônica por intermédio dos quais a apreciação de obras literárias e outros documentos de origem digital podem de fato se efetivar. Em solo brasileiro, semelhante à dinâmica adotada em países do exterior, os leitores digitais - denominação pela qual também se fazem populares entre os adeptos são licenciados por livrarias. À título de ilustração, mencionamos os e-readers Kindle, Kobo e Lev, respectivamente produzidos pelas livrarias Amazon, Cultura e Saraiva. Elencamos algumas das peculiaridades que caracterizam esses equipamentos, tais como a possibilidade de acionarmos luzes; estruturarmos bibliotecas pessoais e organizarmos obras literárias com base em categorias diversas; adicionarmos espaço ao dispositivo a partir da inserção de cartões de memória; e acessarmos, via wi-fi, livrarias online para que possamos adquirir títulos literários, ademais, conectarmos-nos às redes sociais a fim de compartilharmos as leituras realizadas. Em outras expressões, os e-readers ofertam à leitura, antes um ato simples e solitário, caráter passível de partilha com a comunidade.

A incipiência a qual assinalara os primeiros e-readers lançados no mercado foi ultrapassada no decorrer de alguns poucos anos. História do livro (2008), da autoria do estudioso Frédéric Barbier, elucida-nos a respeito das específicas melhorias propiciadas ao famoso dispositivo em destaque: a possibilidade de variar o tamanho dos caracteres; consultar os dicionários de significados e sinônimos; averiguar a ocorrência de termos; 
e, ainda, tomar algumas notas ${ }^{4}$. Ainda que a obra de Barbier (2008) se constitua basilar ao entendimento em relação à historiografia do suporte literário, devemos considerar que sua publicação, por ter acontecido há mais de uma década, apresenta-nos a preceitos os quais, nesta atualidade, estão fadados a questionamentos ${ }^{5}$. Aliás, indo de encontro às precedentes afirmações propostas por Eco e Carrière (2010) - cuja obra também não é capaz de contornar determinadas obsolescências atuais -, os dispositivos de natureza eletrônica, os próprios e-readers, são hoje manufaturados de maneira a proporcionar aos usuários uma imersão literária até mesmo embaixo d'água, em virtude de sua inusitada resistência à exposição de umidade ${ }^{6}$. É por isso que dizemos que os leitores digitais flexibilizam-se tanto quanto os livros impressos intentam fazer nos dias atuais.

Perscrutando ainda acerca dos suportes de leitura que se originaram a partir da revolução tecnológica e do advento da grande rede, reportamo-nos novamente às contribuições de Pinheiro (2012), uma vez que apresenta-nos a debates concernentes à popularidade dos aparelhos eletrônicos portáteis, mais especificamente os tablets - mas cremos poder estender suas reflexões aos smartphones. A popularidade desses artefatos tecnológicos enquanto instrumentos de leitura, conforme o pesquisador nos afirma, se deve às capacidades multimodais, o que torna a prática de leitura "[...] absolutamente inovadora e amiga do utilizador [...]" (PINHEIRO, 2012, p. 38). Mediante a esses novos estímulos de imersão textual, as facetas da leitura contemporânea protagonizam, enfim, os aportes da autoria de Nicholas Carr em A geração superficial: o que a internet está fazendo com os nossos cérebros (2011), obra também seminal ao nosso escopo teórico.

Para além das distrações promovidas pelo surgimento dos produtos inerentes às inovações tecnológicas - televisão e rádio, por exemplo -, Carr (2011) parece se ater unicamente àquelas que provêm do próprio ambiente virtual no qual o texto a ser lido encontra-se disponibilizado. Para tal professor, a combinação de significativa variedade de informações em uma única tela, independentemente das proporções, dilacera nossas concentrações e faz do conteúdo a ser apreendido algo fragmentado. Compreendemos, portanto, que as vinculações entre leitores e objetos de leitura, até então desprovidas de problemáticas, alteram-se proporcionalmente às possibilidades de ser do texto virtual.

De fato, fomos obrigados a substituir nossas ferramentas especializadas por outras que fossem capazes de nos promover um adequado contexto de imersão textual no ciberespaço. Por esse motivo, constitui-se plausível a necessidade de pleno acesso a meios polivalentes para contatarmos texturas e textualidades eletrônicas (CARR, 2011). Porém, cremos ser admissível argumentarmos contra o posicionamento do supracitado teórico, especialmente se considerarmos o contexto educacional para a realização desses apontamentos. Sabemos que "[...] qualidades da rede trazem benefícios atraentes [...]" (CARR, 2011, p. 131) aos seus navegantes e quanto a isso jamais poderíamos discordar. No entanto, tendo em vista o novo horizonte que se esboça aos jovens nativos digitais, por qual razão o aprofundamento intelectual não poderia ser concebido como algo viável às tarefas online, tal como se crê acontecer no suporte impresso? - "[...] não é o tipo de pensamento que a tecnologia encoraja e recompensa [...]" (CARR, 2011, p. 162).

É sobre essa indagação que são sobrepostos os debates acerca das práticas de escrita e leitura na escola contemporânea, os quais serão dissertados na seguinte seção.

\footnotetext{
${ }^{4}$ Notemos que até mesmo as anotações realizadas nas marginálias das obras impressas puderam ser aderidas às possíveis formas de acolhimento de um texto de natureza virtual.

${ }^{5}$ Especialmente em razão da obsolescência planejada que demarca os tempos líquidos e modernos.

${ }^{6}$ Salientamos a necessidade de também nos atentar a algumas das reflexões outrora propostas por esses críticos. Afinal, ao dissertar a respeito das novas tecnologias digitais, estão sujeitos a tatear sob as obscuridades e efemeridades que tornam o campo temático em destaque suscetível às instabilidades.
} 


\section{Desafios (digitais) à escola contemporânea}

Nossos tempos contemporâneos, interceptados por montante informacional de amplitude considerável, tornaram propício - e imprescindível - o surgimento de novas práticas sociais atreladas à escrita e à leitura. Conforme teorizamos na seção anterior, os atos de escrever e ler passaram por transformações diversas as quais nem mesmo os mais céticos, em suas repentinas abdicações às tecnologias digitais, poderiam algum dia ter conjecturado. Como sabemos, as letras equivalem a signos formadores de palavras, sendo estas correspondentes a significantes que expressam, por conseguinte, algum significado quase sempre a respeito de nosso mundo físico. Desse modo, caminhamos, da alfabetização ao letramento, sem enfrentarmos maiores entraves. Entretanto, é muito provável que nesse ponto se aloque a dificuldade em relação à concepção de muitos sobretudo ainda da escola - no que tange às manifestações no horizonte digital.

Isso, pois se ainda hoje o debate sobre a eficiência deste ou daquele método alfabetizador se faz prevalente no meio educacional, a necessidade de conduzir esse processo de maneira que esteja em consonância ao panorama tecnológico atual consiste em algo cuja discussão se tornou obsoleta há tempos, especialmente se julgarmos a imprescindibilidade de tal abordagem nesta temporalidade. A batalha que antes se estabelecia apenas entre as culturas oral e escrita concede espaço para outro embate sobre o qual temos sugerido nos debruçar neste artigo. A própria cultura digital, per se, é composta por elementos que disputam, entre si, um lugar de destaque. Assim, afirmar que o Letramento Digital se resume exclusivamente à escrita ou à leitura no âmbito virtual se configura incorreção, uma vez que as tecnologias exigem, acima de quaisquer questões oriundas dessas atividades, um posicionamento crítico por parte daqueles que se dispõe a navegar em águas atraentes, porém, ainda desconhecidas - quem sabe seja esse o motivo que nos incute a pluralizá-lo: Letramentos Digitais ${ }^{7}$. Se desde a invenção da prensa de Gutenberg pressupomos novas modulações às práticas da escrita, também não poderia haver objeções em relação à vigência dessa circunstância no cenário digital. Não obstante, a mudança de suportes prevê alterações proporcionais aos letramentos.

Letramento: um tema em três gêneros (2009), da professora Magda Soares, traz ao saber conhecimentos basilares à reflexão que propomos. Segundo a estudiosa, os indivíduos são alfabetizados, porém, em sua maioria, não incorporam a escrita ou a leitura em suas práticas cotidianas (SOARES, 2009, p. 45), o que nos impele a cogitar a ideia de que nem todos os cidadãos submetidos ao processo de alfabetização escolar possuem a competência para utilizar os saberes adquiridos ao seu próprio benefício. Daí advém a noção de letramento, que conquistou visibilidade após seu desenvolvimento em distintos setores da sociedade: representa "[...] a condição que adquire um grupo social [...] como consequência de ter-se apropriado da escrita [...]" (SOARES, 2009, p. 18).

Conforme supramencionamos, os Letramentos Digitais não abarcam somente as práticas de escrita ou leitura; tampouco se restringem ao manuseio das ferramentas que os dispositivos eletrônicos conectados à grande rede têm a nos ofertar, embora esse prisma aparente ser algo corroborado com vigor por Soares em um dos primeiros artigos acadêmicos brasileiros que se propuseram a abordar o tema. "Novas práticas de leitura e escrita: letramento na cibercultura" (2002), publicado no início deste milênio, atém-se apenas a dissertar a respeito de questões tangentes à manifestação do internauta

\footnotetext{
${ }^{7}$ É viável pensarmos que hoje vivemos na era dos Multiletramentos. Cunhado nos anos de 1990 por um grupo de pesquisadores norte-americanos - New London Group -, o termo abarca a multiculturalidade imanente à sociedade globalizada e à multimodalidade que emerge dos textos que nela circulam.
} 
enquanto escritor ou leitor do texto virtual - talvez pelo fato de ainda pouco se conhecer acerca da Internet e suas diversas facetas. Afinal, à época, intentava conquistar espaço.

No contexto educacional, as tecnologias da informação e comunicação (TIC) tornaram suas viabilidades de letramento tanto necessárias quanto certamente possíveis. É no ensaio "Letramento metamidiático: transformando significados e mídias" (2010) que Jay Lemke enumera-nos as habilidades que deveriam possuir os aprendizes quanto às TIC: "[...] habilidades de autoria multimidiáticas, análise crítica multimidiática, estratégias de exploração do ciberespaço e habilidades de navegação [...]" (LEMKE, 2010, p. 461). Apesar de conveniente aos tempos atuais, é preciso reconhecer que nem ao menos nos tradicionais suportes a instituição escolar se preocupa em ensinar seus alunos a integrar desenhos ou diagramas às produções escritas - quando acontece, quase sempre, leitura e análise são efetuadas isoladamente. A multimodalidade, de acordo com Luiz Fernando Gomes, autor da obra Hipertextos multimodais: leitura e escrita na era digital (2010), equivale ao status que um texto pode vir a obter com base nos modos de representação que expõe aos seus leitores, resultando em um produto hipertextual ${ }^{8}$.

Esse tipo de texto é demasiado comum no cotidiano de imersão ciberespacial dos educandos, particularmente os adolescentes. As redes sociais nas quais administram suas próprias contas ou páginas pessoais estão cerceadas por elementos audiovisuais, para além dos triviais textos. São áudios, imagens e vídeos os quais ultrapassam o status de adornos ou ilustrações alusivas ao conteúdo contemplado pelos textos em questão. Na realidade, indicam recursos cuja total ausência implicaria, se não na impossibilidade de inferências, seguramente na dificuldade em relação à abstração quanto à proposta do texto. Dessa maneira, ao produto se atribui uma nova função, podendo ou não constituir aquilo o que Lemke (2010, p. 461) denominou como "[...] espinha organizadora [...]", pois artifícios virtuais são elementos sine qua non no processo de construção de sentido.

Produtos de uma gama de combinações, os textos manufaturados no ambiente eletrônico têm demonstrado a questão com a qual os integrantes do sistema educacional, entre professores e mediadores, devem se atentar. Assim sendo, Lemke (2010, p. 461) diz respeito às combinações das modalidades semióticas que conduzem à significação: "[...] mais do que a soma do que cada parte poderia significar separadamente [...]".

Não apenas a escrita se torna transfigurada por aquilo o que nos impõe a nova era. A leitura que realizamos do contingente textual acessado na grande rede também se torna distinta quando em cotejo às situações de leituras outras, tais como aquelas cujo ato de se debruçar acontece por meio do material impresso ${ }^{9}$. Conforme alertamos ainda na seção precedente, a escrita digital está permeada por aquilo o que nomeamos como texturas eletrônicas, ou seja, as nuances que um produto virtual pode vir a apresentar - e as quais o texto publicado no livro tradicional não necessariamente deixa de possuir. Todavia, deve-se reconhecer que a mídia digital tornou o alcance a essas peculiaridades algo mais simples. Sobre isso, Carr (2011, p. 160) afirma crer que nós, enquanto utentes das máquinas - muitas vezes em detrimento dos velhos blocos de anotações ou livros, por exemplo -, rejeitamos a convenção intelectual da concentração, às vezes solitária e, por isso, escassamente compartilhada. Seus contributos, quando trazidos ao seio da área educacional, influem-nos a pensar que a ética que o livro nos conferiu está em risco ao cogitarmos a ideia de que os discentes recebidos pelas escolas detêm um contato muito

\footnotetext{
${ }^{8}$ Tange a um dos estados que o texto virtual é capaz de assumir. Sua construção no ciberespaço acontece a partir da inserção de hiperlinks que funcionam como portas de acesso a materiais outros, sejam textos propriamente ditos ou recursos audiovisuais relacionados ao tópico abordado.

${ }^{9}$ Isso não quer dizer que um livro impresso não possa propiciar uma leitura sob os moldes dos textos eletrônicos, quase sempre não lineares e não hierárquicos. Porém, partiremos de pressuposto contrário.
} 
maior com o espaço virtual do que com os artigos materiais aos quais historicamente atribuímos as possibilidades de leitura, até enfim acontecer a revolução eletrônica.

Ao acessar esse link de viabilidades, no qual a oferta de circunstâncias para a produção criativa anseia ser tão impetuosa quanto à demanda que parte dos alunos, somos apresentados à possibilidade de nos desfazermos de uma abordagem educacional estritamente logocêntrica e fundamentada em suposições universais, passando a contatar outros prismas de concepção, haja vista que subjacente à exploração virtual encontra-se latente distintos conteúdos, novas formas de recepção e complexos olhares apreciativos.

Claramente, para que o acesso a esse panorama seja permitido, faz-se preciso transpor a parca noção, há muito banal, de que os Letramentos Digitais exercem papel de essencial relevância apenas no que se refere à competitividade no mercado global ou à democratização do acesso à informação (GOMES, 2010). De fato, esses são alguns dos benéficos resultados atrelados à prática de letramento. Porém, o desenvolvimento de um senso crítico apurado, em consonância à realidade vigente, talvez seja o seu ponto de maior positividade. Sendo assim, as barreiras geopolíticas ou as fronteiras espaciais e temporais, responsáveis por impossibilitar ou restringir consideravelmente a partilha de saberes entre os indivíduos, poderão vir a ser, então, desconstruídas. Sob essa tenda, coadunamos com a argumentação sugerida por Gomes (2010, não paginado) de que não basta haver computadores dispostos sobre as mesas dos laboratórios de informática. Acima de tudo, é importante realizarmos ou incitarmos em nossos alunos a utilização dessas ferramentas de modo consciente e espirituoso. O que buscamos salientar é que a materialidade desses artefatos, per se, não gera mudanças de cunho social, por exemplo. O potencial das TIC somente haverá de ser realmente explorado caso os recursos por elas ofertados venham a figurar local de merecido destaque nas práticas escolares ${ }^{10}$.

Enveredando-se por via de debate análoga ao pesquisador, Ana Elisa Ribeiro, em Escrever, hoje: palavras, imagens e tecnologias na educação (2018), também se atém a dissertar sobre esse tópico. Vai além do simples fato de uma instituição de ensino qualquer possuir dispositivos adequados e necessários ao trabalho com as TIC, desfazendo-se da ideia de que deslocar os alunos aos espaços destinados à prática da informática seria o suficiente. Para a autora, considerar não somente a existência, mas especialmente a relevância das novas tecnologias, em especial no contexto educacional, significa entendê-las como o meio para o alcance de possibilidades, e não como o fim. Infortunadamente, apesar das incontáveis histórias de sucesso escolar, "[...] deixamos de conhecer muitas experiências malfadadas, incluindo depoimentos de intolerância e impedimento dos esforços de muitos professores [...]" (RIBEIRO, 2018, p. 115).

Decerto, Gomes (2010, não paginado) alerta-nos para esse vislumbre cada vez mais comum no cotidiano das escolas contemporâneas. Se por um lado se discute sobre a utilização dos computadores conectados à Internet - mencionamos também os tablets e os smartphones - enquanto ferramentas aptas a mediar ensino e aprendizagem de maneira inovadora, por outro, muito ao contrário daquilo o que os tecnoentusiastas poderiam ter almejado, é possível acompanharmos debates acalorados em relação àquilo o quê se crê figurar como malefício à competência comunicativa dos alunos, ou melhor, as novas configurações textuais ofertadas pela virtualidade das telas e do mundo.

Indo de encontro às perspectivas que consideram que os alunos escrevem com maior frequência para além dos muros da escola, deleitando-se nas viabilidades as quais somente o universo digital hoje lhes regala (GOMES, 2010), enfrenta-se, ainda nos dias atuais, extrema dificuldade quanto ao preparo de professores a fim de que possam vir a

${ }^{10}$ Não obstante, ainda que não corresponda ao escopo de nosso discorrer, sobrelevamos a relevância concernente à formação de professores capacitados nessa seara de atuação. 
se tornar capazes de auxiliar a formação das gerações que certamente terão de se ajustar a uma realidade social já dependente das TIC. Compreender o panorama deste milênio é tarefa árdua, especialmente para aqueles que integram o fosso geracional, ideia aludida por Mark Prensky, idealizador da expressão jovens nativos digitais, originalmente presente no artigo "Digital natives, digital immigrants" (2001). Não estamos atribuindo essas tais objeções ao simples fato de se ter nascido imigrante digital. Contrariamente, revelamos a necessidade de entendimento em relação às diferenças de saberes entre as gerações, que deverão conviver em um mundo já conquistado pela eletrônica, amigável a alguns e temido por tantos outros. Ao término do processo, o que deve efetivamente interessar a todos os envolvidos é a compreensão global de que as TIC podem promover caminhos para a melhoria das práticas pedagógicas, caso contextualmente aplicadas.

Também podemos refletir a respeito da intolerância aos diálogos entre as TIC e a escola a partir de outro prisma: estariam os profissionais da Educação a subestimar o potencial de seus jovens alunos? Talvez seja essa uma possibilidade. Porém, isso não faria sentido. Afinal, o que se extrair de circunstância na qual aos discentes, construtores do cenário das novas tecnologias, não é dada a credibilidade de que tanto necessitam para demonstrar suas aptidões? Celebrar o entusiasmo de adolescentes em formação escolar poderá orientar os educadores a concretizar suas expectativas - ou atenuar seus anseios - não somente em relação a esta era, mas seguramente aos próprios aprendizes. As argumentações de Sonia Livingstone no artigo "Internet literacy: a negociação dos jovens com as novas oportunidades on-line" (2011) norteiam-nos sobre esse vislumbre.

Desfazer-se da proficiência desse alunado perpassa por questões atinentes a um sistema educacional deficitário no qual, porventura, quando se preconiza a inserção dos atributos digitais no planejamento institucional, a prática geralmente ocorre de maneira superficial. Garantir o efetivo aprofundamento dos saberes que lhe concerne poderá viabilizar ao público de estudantes a possibilidade de se posicionar para além de um mero receptor dos produtos manufaturados no cerne da cultura digital, tornando-o ativo e disseminador de conteúdos (LIVINGSTONE, 2011). Lemke (2010, p. 475), por seu turno, reitera e ratifica o apontamento, expondo acerca do fato de que assim como não somos capazes de prever as transfigurações propiciadas pelo movimento da revolução tecnológica, similarmente não devemos nos ater a ensinar apenas os letramentos que foram populares durante a metade do século XX. É interessante notabilizarmos que a disposição dos novos letramentos não deve ser desprovida de quaisquer fundamentos. Conceder o apoio pedagógico necessário às gerações de nativos digitais para que enfim possam melhor se situar em meio às multifacetas da atual temporalidade, apesar de muitas vezes já deterem conhecimentos inatos à área, é o que certamente construirá um alicerce sólido ao aprendizado em relação à utilização das TIC e de seus artifícios.

É por isso que as Políticas Públicas de Educação se atrelam invariavelmente a esse tópico. Lemke (2010, p. 470) já havia-nos alertado acerca da construção curricular comum como "[...] um esforço de algumas pessoas para impor seus valores àqueles que provavelmente não concordam [...]". Ao lançarmos um breve olhar sobre algumas das competências específicas das áreas do saber do Ensino Fundamental, de acordo com a Base nacional comum curricular (2019), notabilizamos específica exigência relativa à abordagem das novas tecnologias e sua inserção no processo de ensino-aprendizagem dos conteúdos ministrados, exceto na seara referente ao Ensino Religioso. No campo das Ciências Humanas, preconiza-se a análise em relação à era digital. No que concerne às Linguagens, da Língua Portuguesa às manifestações artísticas, torna-se obrigatório compreender e utilizar as TIC sob os moldes críticos, éticos, reflexivos, significativos nas diferentes condutas sociais, ademais, promover contexto propiciador à utilização das mídias, engendrando situações para a produção de saberes ou a resolução de problemas 
cotidianos que envolvam as tecnologias modernas. Por fim, a respeito da Matemática e das Ciências da Natureza, vemos que as TIC são concebidas como ferramentas aptas à obtenção de resultados - distante dos argumentos defendidos por Ribeiro (2018, p. 115).

Embora consideradas nas práticas escolares diárias, é de conhecimento geral que o uso das TIC se encontra sujeito a inúmeras e particulares questões que vão muito além de sua simples presença em documentos ou diretrizes que norteiam os rumos da Educação Nacional. Problemáticas atreladas à qualificação docente e à má distribuição de recursos podem ser mencionados como os obstáculos que impedem a concretização do cenário inicialmente vislumbrado pela BNCC. Nosso discorrer não objetiva debater esse mote, no entanto, recordamos sua notável prevalência no campo educacional.

Escrever e ler no ciberespaço ou com o auxílio dos equipamentos eletrônicos não corresponde, obviamente, às exclusivas preconizações inerentes ao letramento típico da era contemporânea e informatizada. Tal como nos esclarecem os pressupostos do título temático Letramentos digitais (2012), da autoria de Gavin Dudeney e alguns outros especialistas, a conceituação teórica referente ao letramento sobre o qual aqui nos debruçamos depreende uma compreensão mais ampla e polifônica, uma vez que integra o conjunto de habilidades necessárias não somente à produção ou à interpretação de conteúdos, mas também ao compartilhamento e à concessão de sentido no contexto das TIC. Portanto, entender que a era digital possui letramentos diversos significa concordar com Lemke (2010, p. 464) no que diz respeito ao indispensável letramento informático.

Conhecer os métodos de pesquisa e categorização de dados virtuais, ou mesmo saber como distinguir as informações de natureza fidedigna daquelas que não o são, representam algumas das competências que os aprendizes nativos digitais basicamente deveriam apreender quando circunscritos em uma proposta de ensino calcada na real presença das TIC nas instituições educacionais - para além, é claro, da capacidade de se manifestar, seja por intermédio do ato da escrita ou da leitura. Um exemplo que provém desse campo de discussão se refere aos famigerados memes, geralmente utilizados para fins de satirização quanto aos fatos corriqueiros, empregando-se representações gráficas diversas, das imagens aos vídeos. Apesar da simples estrutura, sua interpretação exige conhecimento de mundo extremamente significativo, o que está sujeito à possibilidade de acesso rápido e também simultâneo à informação. O Letramento Remix é aquele que prevê a importância da "[...] habilidade de criar novos sentidos ao samplear, modificar e/ou combinar textos e artefatos preexistentes, bem como de fazer circular, interpretar, responder e construir sobre outras remixagens no interior das redes digitais [...]" (DUDENEY et al., 2016, p. 55) - em suma, saber navegar e desfrutar desse ato.

Atualmente, refletimos muito sobre o empoderamento dos diferentes grupos culturais, étnicos ou sociais. Não se tornariam desempoderados aqueles que hoje estão nas salas de aula enfileirados, muitas vezes desprovidos do direito de fala, subjulgados à autoridade não apenas dos professores, mas também de outros personagens presentes no cenário educacional, cujos papéis principais são de detentores do conhecimento e não de mediadores para o alcance do saber? Também devemos nos atentar para discutir sobre o empoderamento que ultrapassa os muros das escolas e, por isso, se apresenta para além dos parapeitos das janelas virtuais, porque somente ao descortinar o que deveria ser privilégio de todos e não de alguns poucos é que poderemos propiciar aos aprendizes o acesso à atmosfera contemporânea, tornando-lhes possível escrever, ler e compartilhar suas próprias histórias e experiências para além da escola, do ciberespaço e da vida. 


\section{Considerações Finais}

Em desacordo às apocalípticas previsões proferidas por críticos e educadores preocupados com o futuro da escrita e da leitura, os presságios são muito melhores do que se poderia supor a tais práticas, acima de tudo em relação ao seu fenecimento em meio à ascensão dos dispositivos eletrônicos conectados à Internet.

Assim como foi possível acompanharmos no decorrer deste artigo, se anterior à gênese das novas tecnologias escrever e ler constituíam-se como atos cujo o saber se fazia se não obrigatório, demasiado relevante, após o advento tecnológico tornou-se ignóbil colocar em discussão a necessidade quanto à noção sobre as referidas práticas quando efetivadas no universo propiciado pela virtualidade das telas eletrônicas. Hoje, não basta saber se comunicar ou fazer-se representado, muito menos acreditar que a leitura superficial de algum produto textual se figura adequada à internalização de um conteúdo qualquer, por exemplo. É necessário ir além, porque o crescente alastramento do cenário digital exige-nos um debruçar distinto daquele que aprendemos a realizar junto ao suporte impresso, sobretudo na escola, enquanto estudantes. Possuir o domínio em relação às mais inovadoras técnicas de digitação ou leitura no meio virtual também já se tornou algo obsoleto e desprovido de significância. O que tem sido preconizado vai além dessas habilidades. Superconectar-se, portanto, seria o mais ideal. A plausibilidade da assertiva, porém, tende a ser desastrosa quando transposta ao contexto educacional. Eis aqui uma indagação: a escola contemporânea está mesmo disposta a se conectar?

Se nossa escola não está suficientemente preparada para receber os jovens aprendizes \#superconectados e as TIC - ou pelo menos não pretende tão cedo fazê-lo -, essa atitude orienta nossos olhares a um horizonte mais receado do que a morte da escrita e da leitura tradicionais representou aos conservadores. Privar o aprendizado e o contato com outras viabilidades imanentes aos Letramentos Digitais significa negar ao público discente e docente o acesso à contemporaneidade, já que esta é a era digital.

Apresentamos, aqui, uma última constatação: a revolução tecnológica desatina, desestabiliza e desorganiza a estrutura de uma instituição cujos paradigmas fundadores não mais logram alicerçá-la, tamanha se constitui a inquietude que o espectro digital lhe aflige. Conforme revela-nos Lemke (2010, p. 470), se por acaso "[...] queremos pessoas que sabem coisas que querem saber e pessoas que sabem coisas que são úteis em práticas fora das escolas [...]", devemos refletir o analógico e o digital de modo jamais excludente, mas sempre dialogal. Em movimento de alternância, nunca em migração definitiva ou sem direito de retorno à origem, devem se construir, assim, os navegares de nossos educandos \#superconectados. A viagem é longa... Força e avante!

\section{Referências}

BARBIER, Frédéric. História do livro. São Paulo: Paulistana, 2008.

CARR, Nicholas. A geração superficial: o que a internet está fazendo com os nossos cérebros. Rio de Janeiro: Agir, 2011.

DIEB, Messias; AVELINO, Flávio César Bezerra. "Escrevo abreviado porque é muito mais rápido": o adolescente, o internetês e o letramento digital. In: ARAÚJO, Júlio Cesar; DIEB, Messias (orgs.). Letramentos na web: gêneros, interação e ensino. Fortaleza: Edições UFC, 2009. 
DUDENEY, Gavin et al. Letramentos digitais. São Paulo: Parábola Editorial, 2016.

ECO, Umberto; CARRIÈRE, Jean-Claude. Não contem com o fim do livro. Rio de Janeiro: Record, 2010.

GOMES, Luiz Fernando. Hipertextos multimodais: leitura e escrita na era digital. Jundiaí: Paco Editorial, 2010.

HAYLES, N. Katherine. Literatura eletrônica: novos horizontes para o literário. São Paulo: Global Editora: Fundação Universidade de Passo Fundo, 2009.

LEMKE, Jay L. Letramento metamidiático: transformando significados e mídias. Trabalhos em Linguística Aplicada, Campinas, v. 49, n. 2, p. 455-479, jul./dez., 2010.

LIVINGSTONE, Sonia. Internet literacy: a negociação dos jovens com as novas oportunidades on-line. Revista Matrizes, São Paulo, v. 4, n. 2, p. 11-42, jan./jun., 2011.

MINISTÉRIO DA EDUCAÇÃO. Base nacional comum curricular. 2019. Disponível em: http://basenacionalcomum.mec.gov.br/abase. Acesso em: 20 mar. 2020.

MURRAY, Janet. H. Hamlet no holodeck: o futuro da narrativa no ciberespaço. São Paulo: Itaú Cultural: Editora Unesp, 2003.

PINHEIRO, Carlos. Novos cenários e suportes de leitura. In: SOUSA, Sérgio Guimarães de; MORGADO, Evandro (orgs.). As novas tecnologias e a literatura infantil e juvenil: cenários e desafios. Braga: Edições Vercial, 2012.

PRENSKY, Marc. Digital natives, digital immigrants. On The Horizon, oct., 2001, v. 9, n. 5, p. 1-6.

RIBEIRO, Ana Elisa. Escrever, hoje: palavra, imagem e tecnologias digitais na educação. São Paulo: Parábola, 2018.

SOARES, Magda. Novas práticas de leitura e escrita: letramento na cibercultura. Educação e Sociedade, Campinas, v. 23, n. 81, p. 143-160, 2002.

. Letramento: um tema em três gêneros. Belo Horizonte: Autêntica, 2009.

Recebido em 13 de agosto de 2020

Aceito em 14 de novembro de 2020 